Círculo de Lingüística Aplicada a la Comunicación ISSN: $1576-4737$

\title{
Creación discursiva del destino turístico y del viajero: Maneras de ver, maneras de ser
}

\author{
Luisa Chierichetti ${ }^{1}$, Giovanni Garofalo ${ }^{2}$, Giovanna Mapelli ${ }^{3}$
}

Recibido: 8 de octubre de 2017 / Aceptado: 30 de octubre de 2017

Resumen. En la comunicación turística resulta de gran interés analizar las prácticas discursivas que rigen el proceso de mercantilización del ocio y la puesta en valor del destino turístico, así como la creación de la identidad del turista/viajero, que, en el entorno digital, se convierte en la figura central, bien como destinatario del mensaje, bien como productor del texto. Hoy en día los discursos se plasman cada vez más en géneros discursivos híbridos en los que se potencian los aspectos promocionales del destino turístico y se cuida la implicación emotiva del interlocutor, también a través de comentarios críticos y quejas. En este nuevo escenario comunicativo, el léxico guía nuestra forma de pensar y puede determinar y modificar nuestra experiencia.

Palabras clave: discurso turístico, género discursivo, turista 2.0, léxico turístico, identidad del turista/viajero

\section{[en] Discourse construction of tourist destination: ways of seeing, ways of being}

Abstract. In tourism communication, it is interesting to look at discourse practices which underpin the commodification of leisure and the promotion of the tourist destination, as well as the discursive creation of the identity of the tourist/traveller. In a digital environment, this latter becomes the central figure, being both the producer of the text and the message recipient. Nowadays discourses increasingly take the form of hybrid genres that emphasise the promotional aspects of the holiday destination and the emotive implication of the receiver, including by means of criticisms and complaints. In this new discursive scenario, lexis guide our way of thinking and can shape or influence our travel experience.

Keywords: tourism discourse, discourse genres, tourist 2.0, tourism lexis, identity of tourist/traveller

Cómo citar: Chierichetti, L., Garofalo, G., Mapelli, G. (2017). Creación discursiva del destino turístico y del viajero: Maneras de ver, maneras de ser. En L. Chierichetti, G. Garofalo, G. Mapelli (eds.), Creación discursiva del destino turístico y del viajero. Maneras de ver, maneras de ser. Círculo de Lingüística Aplicada a la Comunicación 72, 5-14, http://www.ucm.es/info/circulo/72/chierichetti.pdf, http://dx.doi.org/10.5209/CLAC. CLAC.57898

1 Università degli Studi di Bergamo (Italia)

Correo electrónico: luisa.chierichetti@unibg.it

2 Università degli Studi di Bergamo (Italia)

Correo electrónico: giovanni.garofalo@unibg.it

3 Università degli Studi di Milano (Italia)

Correo electrónico: giovanna.mapelli@unimi.it 
Índice. 1. La práctica de la construcción discursiva del destino turístico y de la identidad del turista/viajero. 2. Géneros discursivos y turismo 2.0. 3. Aspectos léxicos del discurso turístico. Agradecimientos. Bibliografía.

\section{La práctica de la construcción discursiva del destino turístico y de la identidad del turista/viajero ${ }^{4}$}

Es sabido que el lenguaje es un fenómeno social y que existe una relación íntima y dialéctica entre el lenguaje y la sociedad: cuando las personas hablan, escriben, leen o escuchan, suelen hacerlo de una forma socialmente predeterminada, reflejo de relaciones y contingencias socio-económicas, políticas y culturales (Boniburini 2009: 19). La vida social en la que los hablantes se encuentran inmersos es, por tanto, el resultado de prácticas sociales, entre las que destaca la actividad fundamental de la producción del sentido en lo referente a personas, ideas, eventos o lugares, producción que se logra a través de un uso apropiado del lenguaje y de su poder poiético, creador del mundo. El lenguaje, por ende, contribuye de manera decisiva a edificar la realidad que nos rodea y es, en sí mismo, una práctica social (Fairclough 1992, 2001, 2006).

Entender cualquier discurso como práctica social implica concebir la comunicación como un proceso que trasciende las palabras de un texto, para privilegiar las dinámicas que rigen su producción e interpretación, puesto que existe un nexo evidente entre las propiedades (gramaticales, semióticas, sintácticas, etc.) textuales y los recursos cognoscitivos a los que los destinatarios están llamados a acudir para procesar, interpretar y producir los textos.

Asimismo, los discursos plasman géneros específicos, a saber, maneras preconcebidas de interactuar y de vivir la realidad social, en conformidad con estilos preestablecidos, empleados por los hablantes a la hora de definir su identidad y expresar sus exigencias y deseos.

En el caso del discurso turístico, resulta de gran interés analizar las prácticas discursivas que rigen el proceso de mercantilización del ocio y la puesta en valor del destino turístico, forjando, a la vez, la identidad cambiante del turista/viajero ${ }^{5}$. Este enfoque socio-construccionista, según el cual la imagen de un destino turístico determinado 'se construye' y 'se negocia' a través del lenguaje, constituye la temática

${ }^{4}$ El epígrafe 1 de esta presentación ha sido redactado por Giovanni Garofalo, el 2 por Giovanna Mapelli, el 3 por Luisa Chierichetti.

5 Para identificar al sujeto activo de la experiencia turística, algunos autores prefieren "viajero" a "turista" (p. ej., Calvi 2006a: 67), ya que la palabra turista suele asociarse a quien "compra paquetes organizados y es incapaz de interactuar con el entorno real del viaje", mientras que la palabra viajero suele emplearse en sentido más amplio, haciendo hincapié en modalidades de turismo menos estandarizadas y más orientadas a la búsqueda personal. En esta introducción empleamos turista/viajero para abarcar a ambas tipologías de sujetos. 
vertebradora del presente número monográfico de CLAC -dividido en dos entregas por razones editoriales- en el que investigadores de universidades españolas e italianas, volcados en el estudio de la comunicación turística, profundizan, con diferentes metodologías, en aspectos específicos de la 'plasmación discursiva' de la experiencia turística. Las reflexiones introductorias desarrolladas en este preámbulo harán referencia, por tanto, a las temáticas que, cual hilo conductor, enlazan los contenidos de los estudios ofrecidos en la presente entrega.

Conjugando metodologías cuantitativas y cualitativas de investigación, cada uno de los trabajos presentados desarrolla un aspecto específico de la mencionada perspectiva constructivista, para poner de relieve los mecanismos discursivos que determinan la formación de la imagen del destino turístico en la mente de los viajeros potenciales, sobre todo en la fase anterior a la experiencia del viaje. De hecho, está demostrado que, desde el punto de vista psicológico, la elección de un determinado destino vacacional depende en amplia medida de la idea de ese lugar que el viajero llega a autorrepresentarse, a falta de un conocimiento directo adquirido en anteriores visitas (Miossec 1977; Maeran y Novello 1991). A este respecto, cabe recordar que varios estudios de psicolinguística aplicada (Chon 1990; Baloglu y McCleary 1999; Cortini 2002) han concluido que la experiencia del viaje suele ir precedida por una fase de documentación, consistente en la búsqueda más o menos concienzuda de información relevante sobre la localidad que se desea conocer. Se trata de una etapa fundamental del compromiso agentivo del turista/viajero, ya que la elección consciente e informada de un destino turístico y de los productos ofertados en el mercado del ocio depende de la información puesta al alcance del visitante potencial (Fodness y Murray 1998: 503; Cortini 2002: 108). A partir de esta información -obtenida a través del material promocional ofrecido por los operadores turísticos, organismos institucionales, medios de comunicación o mediante las redes sociales- se forja la imagen previa del destino vacacional, que no refleja necesariamente la realidad de ese lugar concreto, sino su simulacro, 'construido' y negociado por los usuarios a través de los géneros consultados (Mininni 2000).

Es interesante observar que la mayoría de los estudios sobre la construcción discursiva del destino turístico suelen centrarse en la comunicación para o entre usuarios durante la fase de planificación/anticipación del viaje, mientras que se conocen menos las dinámicas discursivas que plasman las etapas posteriores, a saber, el viaje de ida hacia el destino elegido, el comportamiento en el lugar visitado, el viaje de vuelta y la fase del recuerdo de la experiencia vivida. Esta última fase suele conllevar una nueva percepción del ambiente doméstico y una serie de conductas generadas por las vivencias acumuladas al visitar nuevos parajes, como el deseo de mantener un contacto con el lugar visitado (p. ej., siguiendo las noticias en los medios de comunicación relacionadas con este) o de cultivar nuevas aficiones descubiertas a lo largo del viaje. A este respecto, se ha observado que la verdadera conclusión de la experiencia turística (p. ej., el intercambio de recuerdos con los compañeros de viaje o la descripción de la experiencia a familiares y amigos) coincide con una fase de evaluación de las vivencias, generadora de nuevos deseos y proyectos vacacionales (Cortini 2002: 109). En consonancia con una tendencia epistemológica general, también los estudios 
contenidos en este número se centran, sobre todo, en la descripción de mecanismos discursivos observables en géneros que ofrecen información clave para la fase de planificación del viaje (guías turísticas, folletos, páginas web institucionales de promoción turística o de empresas de servicios de alojamiento, blogs de viajeros o foros de prensa digital, etc.), que permiten observar cómo los operadores turísticos guían la representación mental previa del lugar vacacional o bien cómo los potenciales usuarios de los servicios de ocio interactúan entre sí, negociando y construyendo una imagen más o menos ilusionante de lugares todavía inexplorados. Así pues, esa imagen previa puede construirse discursivamente a través de nuevas plataformas de expresión, como los foros de la prensa digital (véase el estudio de Ortega Garrido), o bien recurriendo a herramientas de la economía colaborativa, como las guías de vecindarios de la plataforma Airbnb, que utilizan estrategias encaminadas a promover una determinada visión de la experiencia turística y a consolidar en el viajero un sentimiento de pertenencia a un ingroup constituido por una comunidad virtual (véanse las reflexiones propuestas por Bani).

La construcción de dicha imagen es necesariamente un proceso de índole cognitiva, que depende de los filtros culturales y sociales mediante los cuales los individuos "leen el mundo" (Potter 1996, Cole 1996). Asimismo, la perspectiva socio-constructivista de la comunicación turística permite realizar una investigación de tipo dinámicoprocedimental, capaz de describir no solo los efectos producidos en los potenciales turistas por determinadas informaciones, sino también los procesos discursivos de formación de estos efectos, entre los cuales se incluyen los procesos de creación de la identidad social del turista (aspecto analizado por Dolón), de su subjetividad (p.ej., a través de las quejas manifestadas en la plataforma TripAdvisor, estudiadas por Suau Jiménez) o de su dimensión sensorial, cognitiva y afectiva (explorada por Soto, con especial referencia al papel discursivo de los verbos de percepción).

La adopción de tal perspectiva ofrece, por tanto, la ventaja de evidenciar cómo la imagen de un determinado destino turístico se plasma discursivamente para satisfacer las necesidades del viajero, mediante un proceso esencialmente interactivo, y cómo el viajero negocia su propia identidad como miembro de una comunidad en la que se reconoce.

A este propósito, cabe recordar que la investigación de corte psicolingüístico sobre la construcción discursiva del lugar vacacional parece demostrar que la necesidad primaria del viajero consiste, ante todo, en conocerse a sí mismo. De hecho, aunque la experiencia del viaje suponga necesariamente el encuentro con el "Otro", el individuo suele vivirla como una ocasión privilegiada para volver a descubrir y afianzar su propia identidad (Albanese 2000, Galvani 2000, en Cortini 2002: 109). No es por casualidad que Bruner (1991) mantiene que, en el fondo, el viaje no constituye tanto una apertura hacia nuevos conocimientos, como una experiencia mediante la cual el turista/viajero tiende a reafirmar y consolidar su propia visión del mundo. Este comportamiento ha sido explicado en términos de "disonancia cognitiva" (Gullotta 1997) entre el universo cultural al que pertenece el viajero y el 'nuevo mundo' que el destino turístico representa. Desde esta perspectiva, la experiencia turística se configuraría como un 
delicado equilibrio entre la reafirmación de sí mismo y el atractivo ejercido por el 'Otro' (Cortini 2002: 111), detectable, por un lado, en la apertura hacia la naturaleza y al patrimonio universal ajeno (p. ej., los museos o los yacimientos arqueológicos, considerados como 'herencia cultural universal') y, por otro, en cierta cerrazón hacia la cultura íntima del 'Otro' (a saber, las peculiaridades e idiosincrasias culturales de pueblos distintos).

\section{Géneros discursivos y turismo 2.0}

Es bien conocido que los géneros discursivos son eventos comunicativos creados socialmente, en los que varían la organización textual, los roles de los interlocutores, la carga informativa, los rasgos lingüísticos y las implicaciones extralingüísticas (Swales 1990). Se conciben como prácticas comunicativas situadas (situated communicative practices, Hanks 1987) en un determinado contexto histórico y social y como modelo abstracto y estable que funciona como molde para el hablante y como horizonte de espera para los destinatarios o para los miembros de una comunidad.

Sin embargo, las transformaciones socioculturales pueden conllevar cambios significativos en las pautas textuales convencionales (Garzone 2007).

En particular, por lo que atañe a la comunicación turística, el concepto de género es fundamental para reflejar la complejidad y heterogeneidad de la producción textual. Calvi (2010) propuso una taxonomía jerarquizada con una finalidad eminentemente operativa de los géneros utilizados en este sector profesional, aplicando un modelo multifuncional y multidimensional que conjugaba los aspectos formales con la perspectiva pragmática y sociocrítica.

En la actualidad, no obstante, la irrupción de la comunicación a través de Internet y la multimodalidad han determinado una fuerte tendencia a la hibridación. La Red ha engendrado la recontextualización (Linell 1998) de muchos textos turísticos, creando nuevos horizontes de expectativas y dando origen a nuevos géneros fronterizos en los que se rompen los esquemas tradicionales y se mezclan rasgos preexistentes en nuevas combinaciones inéditas. En particular, en el entorno digital se han potenciado los aspectos promocionales, se cuida constantemente la implicación emotiva del interlocutor, mediante la sensorialidad, la cognición y la afectividad en la construcción anticipada de la experiencia turística (véase el estudio de Soto Almela), se rastrea una marcada tendencia a la oralización y una presencia no secundaria de comentarios críticos y quejas (véanse los trabajos de Suau Jiménez y de Ortega Garrido). Incluso la guía de viaje, género bien codificado y fácilmente reconocible, en los últimos años, ha ido reconfigurando algunos de sus rasgos convencionales debido al desarrollo de la comunicación en la Web (Calvi 2016; Mapelli 2016). Además de los múltiples formatos en los que se presenta, de la prominencia de elementos persuasivos más que informativos, se destaca un nuevo tipo de guía, denominada "colaborativa" (véase el 
estudio de Bani), es decir, hilvanada por autores múltiples que mezclan distintos testimonios personales.

Por otro lado, en este nuevo ambiente comunicativo encontramos la variante turística de los géneros propios de Internet, entre los que sobresalen las páginas web, los blogs, los foros, las opiniones o reseñas de los viajeros o los comentarios de prensa digital (estudiados por Ortega Garrido), que fomentan la participación de los viajeros en la difusión de información y de sugerencias y recomendaciones, como la discusión entre profesionales.

La tecnología 2.0 propicia también el activismo del turista/viajero que modifica la manera de percibir el viaje, de utilizar los textos y de vender los productos (López Alonso 2015). En el ciberespacio, que ya no es solo un repositorio de datos, surgen nuevas formas comunicativas en las que adquieren especial relevancia la interactividad y la ubicuidad, es decir, la posibilidad de actuar con otros actores sociales y de acceder a los mismos contenidos desde cualquier parte del mundo (Yus Ramos 2010). De hecho, el viajero de hoy tiene la posibilidad de compartir en tiempo real las experiencias con los otros miembros de la comunidad de viajeros.

El nuevo turista 2.0 logra, por tanto, un diferente grado de madurez, está más informado, preparado y dispuesto a crear y a confeccionar su proprio viaje para personalizar su tiempo libre sin necesidad de intermediarios (Granieri y Perri 2010); en segundo lugar, tiene una mayor demanda de información práctica y está más interesado en las experiencias vivenciales más auténticas (como nos demuestra Bani) que puede realizar en el destino más que en las características intrínsecas del lugar que quiere visitar; y, por último, mediante su hiperconectividad y su participación en las redes sociales y en las comunidades de viajeros, llega a poner en tela de juicio el discurso de los expertos. Es más, el usuario, de acuerdo con su deseo de afianzar su propio ethos, asume él mismo el papel de experto, intercambiando opiniones y valoraciones sobre los destinos y productos turísticos. La credibilidad del turista 2.0 se fundamenta en su condición de testigo, que llega a ser divulgador de conocimientos sobre los lugares visitados, de experiencias vividas y a proporcionar información práctica útil para otros miembros de la comunidad de viajeros (Calvi 2010, 2016). Así pues, el turista 2.0 se convierte en la figura central, sea como destinatario del mensaje sea como productor del texto ('prosumidor', Toffler 1980) en el marco de un proceso colaborativo y participativo de la construcción del destino turístico. Sin embargo, no hay que olvidar que esta producción de contenidos generados por los usuarios puede ostentar una democratización del saber que, en realidad, resulta ser un espejismo tras el cual se oculta una brillante maniobra de marketing relacional (Metitieri 2009). De hecho, a menudo, las empresas aprovechan las herramientas del medio para controlar nuestros gustos y preferencias. Por lo tanto, aunque está comprobado que la comunicación turística digital se está convirtiendo en la fuente más utilizada, como lo demuestran también los estudios recogidos en este volumen, y es la que más influye en la imagen del destino y en la selección del mismo (Andrade Suárez 2012), hay que saber reconocer la credibilidad y la fiabilidad de la información que suministra. 


\section{Aspectos léxicos del discurso turístico}

La atención por los aspectos lingüísticos del fenómeno turístico se ha desarrollado de manera tímida y paulatina, con respecto al interés que ha despertado de manera interdisciplinar en distintos ámbitos que van desde la economía hasta la antropología, pasando por la sociología y la psicología (Calvi 2006a: 7). Esta demora se debe fundamentalmente a la dificultad de trazar los contornos de un lenguaje híbrido, ya que el turismo encierra un conjunto de manifestaciones heterogéneas difíciles de aprehender y clasificar (Calvi y Mapelli 2011: 10). En la lengua del turismo no se da una progresiva divulgación de los contenidos teóricos según el nivel de especialización, sino una combinación de múltiples actividades y disciplinas que, desde el punto de vista textual, pueden agruparse en los bloques de la reflexión teórica, la gestión, y la descripción y promoción del destino turístico (Calvi 2010: 18-19).

Desde el punto de vista léxico, por un lado, es indiscutible la presencia dominante de la lengua general (Calvi y Mapelli 2011: 10); por otro, es evidente la presencia de componentes temáticos que participan en la descripción del producto turístico desde los muchos y distintos sectores profesionales implicados (Alcaraz Varó et al. 2000): economía, geografía, historia del arte, gastronomía, deporte, etc. (Calvi 2006a, 2011). Calvi (2006b: 291) también nota que a un léxico cargado de internacionalismos, especialmente en el ámbito de la organización turística, se le contrapone la tendencia a revalorizar el patrimonio local que tiene significativas repercusiones lingüísticas.

Esta inicial dificultad se ha superado con la adopción, a nivel del estudio de las lenguas especiales, de una perspectiva basada en la noción de género (Calvi 2010) y centrada en la diversificación discursiva (Cabré 1999), que permite situar términos y conceptos en su contexto. En la misma línea, la teoría sociocognitiva de la terminología (Temmerman 2000) nos indica que la lengua general y la polisemia garantizan la adaptación flexible de los términos a los diferentes contextos: términos y conceptos no existen como unidades independientes, sino que son dinámicos y variables, también diacrónicamente, en relación con su función en el discurso y en los géneros específicos. La realización del discurso de especialidad no se limita a la comunicación entre especialistas, sino que tiene destinatarios diferentes y, por lo tanto, participa de diferentes grados de variación natural (Cabré 2005: 44). Así, si, por un lado, la investigación sobre las lenguas especiales se ha ido desplazando desde una perspectiva esencialmente léxica hacia un enfoque comunicativo y pragmático (Calvi 2006a: 13), por otro lado, esta nueva perspectiva ha permitido renovar el interés académico hacia la cuestión léxica y terminológica, aunque, en el caso del turismo, no todo el léxico puede considerarse susceptible de una elaboración terminológica (Santos López 2011: 250).

Sin duda, un gran aliciente para la investigación basada en el léxico ha sido la apertura de los géneros textuales del turismo, que resultan ser relativamente estables (Calvi y Mapelli 2011: 10), hacia las oportunidades de la tecnología digital: en la Web 2.0, el discurso turístico ha experimentado una enorme expansión en un eje horizontal sin barreras espacio-temporales (Mapelli 2016: 150), en el que, como vimos en \$2, el turista/viajero/usuario es un consumidor que a su vez crea contenidos. Un ejemplo interesante de este proceso es el uso de las redes sociales por parte de los operadores 
turísticos, en el que el discurso promocional se reinterpreta y recontextualiza (Linell 1998: 153) "conversacionalizándose" (Fairclough 1995) y pasando de una dimensión monologal a una dialógica. Con todo, conviene establecer una distinción nítida entre la escritura sincrónica o interactiva (chats, blogs, o las guías colaborativas analizadas por Bani) y la escritura asincrónica o unidireccional (como es el caso los sitios web de promoción institucional estudiados por Soto Almela) (Rodríguez Abella 2011:156).

De hecho, la ambigüedad de roles entre el turista/viajero y el usuario de sitios web corrobora la finalidad esencialmente promocional y comercial del discurso turístico en la Red, en la que la finalidad persuasiva llega a primar sobre la función informativa o referencial, favoreciendo la aparición de los aspectos interpersonales del metadiscurso (Mapelli 2016: 170). En este número monográfico, el ensayo de Dolón apunta a trazar esta caracterización del turista como consumidor de una ambientación hotelera creada por la oferta de lo abstracto, especialmente en relación con el espacio y la ubicación. También el estudio cualitativo de Bani trata de la mercantilización y de la hibridación de la lengua del turismo, señalando, además, la acuñación de nuevos términos cuyo significado se establece de común acuerdo entre los miembros de la comunidad interesada, con el procedimiento de la 'derivación fabricada' (Calvi 2006a: 60). Al centrarse en algunos géneros discursivos de la Web 2.0, los estudios identifican las áreas léxicas relacionadas con los objetivos de persuasión y transmisión de valores, sin detenerse en el núcleo de términos más específicos y en las unidades terminológicas procedentes de los sectores profesionales relacionados con el turismo (Calvi 2009: 203). De hecho, los aspectos léxicos tratados abarcan el proceso de valorización del destino turístico y de mercantilización del ocio, basándose en recopilaciones electrónicas de distintas características y dimensiones. El estudio de Soto Almela observa rasgos persuasivos en verbos perceptivos en un corpus de páginas web institucionales de promoción turística, en la que no es posible la interacción con los usuarios. Sin embargo, la intención persuasiva no se halla solo en una dimensión vertical -de parte de quien oferta un servicio turístico hacia el cliente- sino también en la línea horizontal de la comunidad de viajeros que comparte sus experiencias. Uno de los espacios más acreditados para el intercambio de información turística entre pares, es decir, entre turistas, es la plataforma de Tripadvisor, utilizada por Suau Jiménez para estudiar la transmisión de la subjetividad y a la persuasión a través de las críticas y quejas sobre hoteles, que se utilizan para la fidelización de los clientes con fines promocionales (Mapelli 2016: 171). En conclusión, no podemos no estar de acuerdo con Temmerman (2000: 237): el léxico del discurso turístico tiene el poder de guiar nuestra forma de pensar y, por ende, el poder de determinar y modificar nuestra experiencia.

\section{Agradecimientos}

Expresamos nuestro sincero agradecimiento al equipo de dirección y de redacción de Círculo de Lingüística Aplicada a la Comunicación por la oportunidad de publicar este volumen monográfico en el marco de la revista. Asimismo, este volumen no se hubiera podido realizar sin la colaboración esencial de los evaluadores anónimos, cuyos valiosos comentarios han contribuido a enriquecer el contenido científico de los artículos presentados. 


\section{Bibliografía}

Albanese, A. 2000. "Viaggiare per conoscersi: dall'identità all'identità sociale". En Gabassi, P.G.; Togni, M. (eds.).Viaggiare per conoscersi. Milán: CUEM, 1-10.

Alcaraz Varó, E. et al. 2000. Diccionario de términos de turismo y de ocio. InglésEspañol Spanish-English. Barcelona: Ariel.

Andrade Suárez, M.J. 2012. "El uso de internet como fuente de información turística: Propuesta metodológica para el análisis de su importancia en la creación de la imagen del destino". Papers de turisme, 52: 44-62.

Baloglu, S.; McCleary, K.W. 1999. "Comparative study of tourism perceptions". Annals of Tourism Research, 26/4: 869-897.

Boniburini, I. 2009. "Linguaggio, discorso e potere. Perché le parole non sono solo parole”. EnBoniburini, I. (ed.).Alla ricerca della città visibile. Florencia: Alinea: 19-32.

Bruner, E.M. 1991. "Transformation of Self in Tourism". Annals of Tourism Research, 18: 238-250.

Cabré, M.T. 1999. Terminology: Theory, Methods, and Applications. Amsterdam/Philadelphia: John Benjamins.

Cabré, M.T. 2005 [1999]. La Terminología: Representación y Comunicación. Elementos para una teoría de base comunicativa y otros artículos. Barcelona: IULA-Universidad Pompeu Fabra.

Calvi, M.V. 2006a. Lengua y comunicación en el español del turismo. Madrid: Arco/Libros.

Calvi, M.V. 2006b. El uso de términos culturales en el lenguaje del turismo: los hoteles y su descripción. En Calvi, M.V.; Chierichetti, L. (eds.). Nuevas tendencias en el discurso de especialidad. Berna: Peter Lang: 271-292.

Calvi, M.V. 2009. "El lenguaje del turismo". En Calvi, M.V. et al.(eds.). Las lenguas de especialidad en español. Roma: Carocci: 199-224.

Calvi, M.V. 2010. "Los géneros discursivos en la lengua del turismo; una propuesta de clasificación”. Ibérica, 19/2: 9-32.

Calvi, M.V. 2011. "Pautas de análisis para los géneros del turismo". En Calvi, M. V.; Mapelli, G. (eds.). La lengua del turismo. Géneros discursivos y terminología. Berna: Peter Lang: 19-45.

Calvi, M.V. 2016. "Guía de viajes y turismo 2.0: Los borrosos confines de un género". Ibérica, 31: 15-38.

Calvi, M.V.; Mapelli G. 2011. "Introducción". En Calvi, M.V.; Mapelli G. (eds.). La lengua del turismo. Géneros discursivos y terminología. Berna: Peter Lang: 9-16.

Chon, K. 1990. "The role of destination image in tourism: a review and discussion". Revue de Tourisme, 45/2: 2-9.

Cole, M. 1996. Cultural Psychology. Cambridge, Mass.: Harvard University Press.

Cortini, M. 2002. "La costruzione discorsiva della meta turistica: uno studio di psicolinguistica applicata". Journal of Applied Psycholinguistics, II/3: 107-124.

Fairclough, N. 1992. Discourse and Social Change. Cambridge UK: Polity Press.

Fairclough, N.1995. Media Discourse. Londres: Edward Arnold.

Fairclough, N. 2001. Language and Power. Londres: Longman. 
Fairclough, N. 2006. Language and Globalization. Londres: Routledge.

Fodness, D.; Murray, B. 1998. "A typology of tourist information search strategies". Journal of Travel Research, 37/2: 108-119.

Galvani, A. 2000. "Pulsioni e motivazioni". En Gabassi, P.G.; Togni, M. (eds.). Viaggiare per Conoscersi. Milano: CUEM: 121-136.

Garzone, G. 2007. Multimodality in corporate communication. Milano: Franco Angeli.

Granieri, G.; Perri, G. 2010. Linguaggi digitali per il turismo. Milano: Apogeo.

Gullotta, G. 1997. Psicologia Turistica. Milano:Giuffré.

Hanks, W. F. 1987. "Discourse genres in a theory of practice". American Ethnologist, 14/4: 668-692.

Linell, P.1998. "Discourse across boundaries: On recontextualizations and the blending of voices in professional discourse". Text, 18/2: 143-157.

López Alonso, C. 2015. "Ciberturismo y transidisplinariedad". En Piñeiro Maceiras, M.; Chapuis, L.; Re, M. (eds.). Turismo y representación espacial. Madrid: Servicio de Publicaciones de la Universidad Rey Juan Carlos: 7-22. http://hdl.handle.net/10115/12521[1/10/2017]

Maeran, R.; Novello, C. 1991. Tour-ist. Psicologia e Turismo. Padova:Cleup.

Mapelli, G. 2016. “Guías de viaje 2.0: léxico y metadiscurso”. Ibérica, 31: 149-174.

Metitieri, F. 2009. Il grande inganno del Web 2.0. Roma-Bari: Laterza

Mininni, G. 2000. Psicologia del Parlare Comune. Bologna: Grasso Editori.

Miossec, J. M. 1977. 'L'Image Touristique comme introduction à la géographie du tourisme", Annales de Géographie, 86: 55-70.

Potter, J. 1996. Representing Reality. Discourse, Rhetoric and Social Construction. Londres: Sage.

Rodríguez Abella, R.M. 2011. "La lengua de la promoción turística en el sitio www.turismodecanarias.com". En Calvi, M.V.; Mapelli, G. (eds.). La lengua del turismo. Géneros discursivos y terminología. Berna: Peter Lang: 153-175.

Santos López, J. 2011. "El glosario Linguaturismo: aplicación del enfoque de géneros a la terminología”. En Calvi, M.V.; Mapelli, G. (eds.). La lengua del turismo. Géneros discursivos y terminología. Berna: Peter Lang: 153-175.

Swales, J. M. 1990. Genre analysis. Cambridge: Cambridge University Press.

Temmerman R. 2000. Towards New Ways of Terminology Description. Amsterdam/Philadelphia: John Benjamins.

Toffler, A. 1980. The Third Wave. Nueva York: William Morrow.

Yus Ramos, F. 2010. Ciberpragmática 2.0. Nuevos usos del lenguaje en Internet. Barcelona: Ariel. 